\title{
Irregular wave transmission over a submerged breakwater
}

\author{
M BABA \\ Centre for Earth Science Studies, Regional Centre, Cochin 682018, India
}

\begin{abstract}
Irregular wave tests were conducted in a laboratory flume with an 'Odessa-type' bevelled-block submerged breakwater on a sloping bottom. The incident and transmitted waves were subjected to probabilistic and spectral analysis. Although the incident wave heights and periods are described respectively by the Gluhovski and the Rayleigh distributions, for the square of the wave periods, the transmitted heights and periods conform to the Rayleigh distribution irrespective of the depth of submergence of the breakwater. The significant wave heights $\left(H_{s}\right)$ give transmission coefficients comparable to the corresponding monochromatic waves, but the $H_{\max }$ and $\bar{H}$ give $50 \%$ higher and upto $28 \%$ lower values respectively, the difference increasing with the depth of submergence of the break water. The peak frequency of the spectrum does not vary on transmission. Resonant frequencies, where the wave energy is transmitted almost completely, are observed in the process. The resonance occurs at frequencies $1.4,3 \cdot 8,5.6$ and $7.0 \mathrm{rad} / \mathrm{s}$, and they remain constant for different submergences of the breakwater. The presence of similar frequencies is also found in the case of monochromatic waves, although the tests are limited. Application of irregular wave tests is recommended in the design of submerged breakwaters.
\end{abstract}

Keywords Submerged breakwater; irregular waves; probability distribution; wave spectrum; resonant frequencies; transmission coefficient.

\section{Introduction}

At present most of the shore protection projects are confined to the shoreline and experience has shown that without advance breaking of the waves, these measures seldom protect the coasts or even themselves. By advance breaking or damping of waves in the offshore itself, the wave action on the beach or on the shore structures is reduced and the movement of the beach sediment to the offshore is curtailed. Offshore submerged breakwaters are suitable in such cases, both on technical and economic grounds (Baba 1981; Erattupuzha \& Raman 1976). These also have environmental and aesthetic advantages (Dick \& Brebner 1968; Baba 1981).

Most of the studies on the wave transmission of submerged breakwaters were conducted in laboratory flumes with regular waves. Actual waves in the sea are irregular. As the design of a submerged breakwater is mainly based on a particular design regular wave (Seelig 1980; Lizlov \& Natalchishin 1970; etc) and the structure when constructed is exposed to natural irregular waves, a clear understanding of the performance of the structures both on exposure to regular and irregular waves is essential to avoid any undesirable aftereffects.

The present study aims at understanding the irregular wave transmission over a submerged breakwater made of impermeable bevelled blocks. The probabilistic and spectral characteristics of irregular waves have been studied and their statistical and

A list of symbols appears at the end of the paper. 
spectral parameters are compared with those of regular waves. Unlike most of the previous studies the submerged breakwater has been studied on a sloping bottom, which represents the true natural conditions.

\section{Previous work}

Wave transmission through impermeable and permeable breakwaters, both submerged and subaerial, has been widely studied and a detailed summary is available in Dick \& Brebner (1968), Baba (1978) and Seelig (1980). Studies related to the transmission of irregular waves over a submerged breakwater are limited. Studies with random laboratory waves were reported by Ergin \& Pora (1971). Ouellet \& Morin (1975), Goda \& Suzuki (1976), Baba (1978), Seelig (1980). Wave transmission under prototype conditions was studied by Nakamura et al (1966), Lizlov \& Natalchishin (1971), Thornton \& Calhoun (1972), Lee \& Walther (1974) and others. Most of the studies treated the wave transmission with either regular waves or irregular waves (in isolation).

The only known investigation, which compares the wave transmission due to regular and irregular waves in absolutely similar model conditions is with a vertical thin barrier and an A-frame floating breakwater (Ouellet \& Morin 1975). It was shown that the response of a structure does not give the same information when subjected to attack by regular and irregular waves. The presence of resonant frequencies, which depend on the characteristics of the structure, in the system was detected by the use of irregular waves. However, their presence in the case of regular waves was doubtful.

Gadre \& Kanetkar (1983) who investigated incident and transmitted wave spectra at a prototype subaerial breakwater, reported an oscillation of transmission coefficient within the effective range of frequencies of the energy spectrum occurring at that location. Minimum transmission was observed at the peak frequency. Thornton \& Calhoun (1972) conducted a large number of experiments in flumes, model basins and in the field, with sloping permeable rubble mound subaerial breakwaters to understand the transmission and reflection of irregular waves. The transmission and reflection coefficients were shown to be strongly dependent on frequency, moderately dependent on tidal stage and slightly dependent on incident wave amplitude. A definite increase in energy transmission towards the lower frequencies was observed, which means that the breakwater acts as a moderately selective transmission filter of short wave energy.

Based on field investigations of a bevelled block impermeable submerged breakwater, Lizlov \& Natalchishin (1971) stated that the distribution of wave heights is the same seaward and shoreward of the structure. This was found to be so in the case of wave periods also. At the same time Shtephan et al (1970) showed that the distribution of both the waves and the periods changes, when the waves pass over a prototype offshore bar.

Recently Seelig (1980), on the basis of two-dimensional tests of wave transmission and reflection characteristics of laboratory submerged breakwaters, concluded that the incident and transmitted wave height distributions have similar shapes. The transmission coefficient for irregular waves was found to be approximately the same as for a similar regular wave test. The mean wave height and period of peak energy density are the parameters recommended for describing irregular waves. Irregular wave tests indicate that the transmitted and reflected spectra have equal or higher spectral peakedness than incident spectra. Joint wave height-period distributions have similar dimensionless shapes for incident and transmitted wave records. 
These studies lead to the conclusion that no single opinion exists regarding the distribution characteristics of wave heights and periods near a submerged breakwater and hence they are yet to be clearly understood. Also the spectral characteristics of irregular waves in the case of submerged breakwaters made of impermeable bevelled blocks have not been studied.

\section{Test procedure}

Laboratory tests were conducted in a wave flume $29.0 \mathrm{~m}$ long, $1.17 \mathrm{~m}$ wide and $1.40 \mathrm{~m}$ deep (figure 1). A flap-type wave generator was fixed at one end of the flume. The wave generator was guided by a variable speed motor and an electronic control unit, which could generate both regular and irregular waves. Regular wave heights upto $18 \mathrm{~cm}$ and periods upto $1.6 \mathrm{~s}$ could be produced in the flume.

For the generation of irregular waves a spectrum suggested by Bao (1969) was used:

$$
S(\omega)=4 A_{0} \frac{\omega^{m} \omega_{p}^{m}}{\left(\omega^{m}+\omega_{p}^{m}\right)^{2}}
$$

where, $\quad m=\pi / \sin ^{-1}\left\{\frac{3}{4}\left[1-\left(\bar{T} / T_{p}\right)^{2}\right]\right\}^{1 / 2}$.

This spectrum is also presented in a nondimensional form:

$$
S\left(\omega / \omega_{p}\right)=4 A_{0} \frac{\left(\omega / \omega_{p}\right)^{m}}{\left[\left(\omega / \omega_{p}\right)^{m}+1\right]^{2}} .
$$

Bao (1969) reported that this simple spectrum corresponds well with measured wave spectra from the Black sea and Atlantic ocean. Mihailov et al (1974) has shown that it corresponds to Caspian Sea conditions also. This spectrum has been used in many investigations (Mihailov et al 1969, 1974; Wiemer \& Halfin 1977; Baba 1978; and others).

For laboratory simulation of irregular waves the basic criteria should be that they follow the Rayleigh distribution (Colonnel \& Perry 1968), the cumulative form (Krilov 1956) of which is written as:

$$
P(H)=\exp \left[-\frac{\pi}{4}(H / \bar{H})^{2}\right] .
$$

In $\$ 4$ (also in figure 4A) it may be seen that the irregular wave heights at the control point (wave gauge B1) show good agreement with the Rayleigh distribution. As a whole

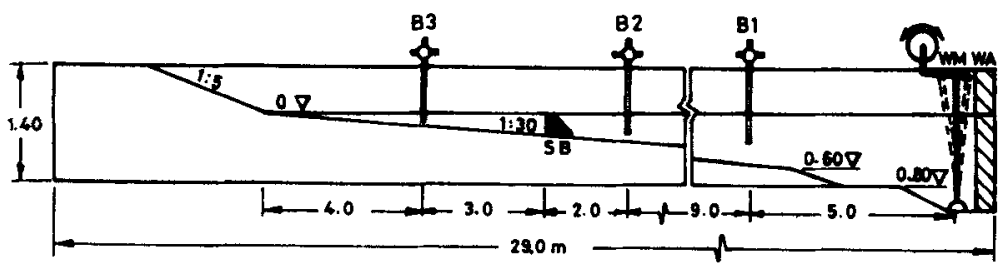

Figure 1. Model test facility (SB-submerged breakwater; B1, B2, B3-wave gauges; WM-wave machine; wA-wave absorber) 
the laboratory studies were conducted under Froude similitude conditions. A relatively large model scale of 1:20 was selected.

The studies reported herein formed a part of the author's investigations on the suitability of submerged breakwaters for coastal protection (Baba 1978) along the south-west coast of India. Hence a typical situation of this part of the coast was used to construct the model. A close similarity has been observed between this situation and the conditions of the Black Sea coast near Odessa. The submerged breakwaters are used widely along the Black Sea coast for coastal protection (Baba 1981). Hence, the submerged breakwater selected for this study was similar to that of Odessa.

A smooth concrete model coast was constructed in the laboratory flume consisting of an underwater slope of 1 on 30 . A smooth concrete submerged breakwater of the 'Odessa-type', with a fronting slope of 1 on 1.67 (figure 2) was constructed with its crest at the low water level, Capacitance-type wave gauges, with a linear calibration, were used to measure the waves. The waves were recorded on a photosensitive recording paper.

For measuring the extent of wave reflection from the submerged breakwater some initial tests were conducted. For this three close wave gauges were placed in front of the structure. The extreme wave gauges were placed so as to measure the minimum and maximum heights corresponding to the node and antinode during the reflection of regular waves. The central gauge was located at the mid-point. A series of tests at three levels of submergence of the breakwater, i.e. $a=0.0,3.8$ and $7.5 \mathrm{~cm}$ were conducted with regular waves keeping the period constant. The incident and reflected wave heights were calculated as in Dick (1968), using the height values obtained from the two extreme wave gauges. The results of this test series are presented in table 1. It is found, as expected, that the reflection coefficient decreases with the increase in depth of submergence, with values occurring between 0.0 and 0.13 . The reflection is negligible $(<0.05)$ especially for intermediate and higher depths of submergence. The wave heights recorded by the intermediate gauge were closer to the incident wave heights calculated using the values of the two extreme gauges (table 1). Hence, for the subsequent tests the incident waves were recorded at this position, thus minimising the influence of reflection in the data. Ergin \& Pora (1971) and Seelig (1980), report that the reflection coefficient is approximately the same for monochromatic and irregular waves for a given value of wave steepness. In the present study, the mean period of irregular

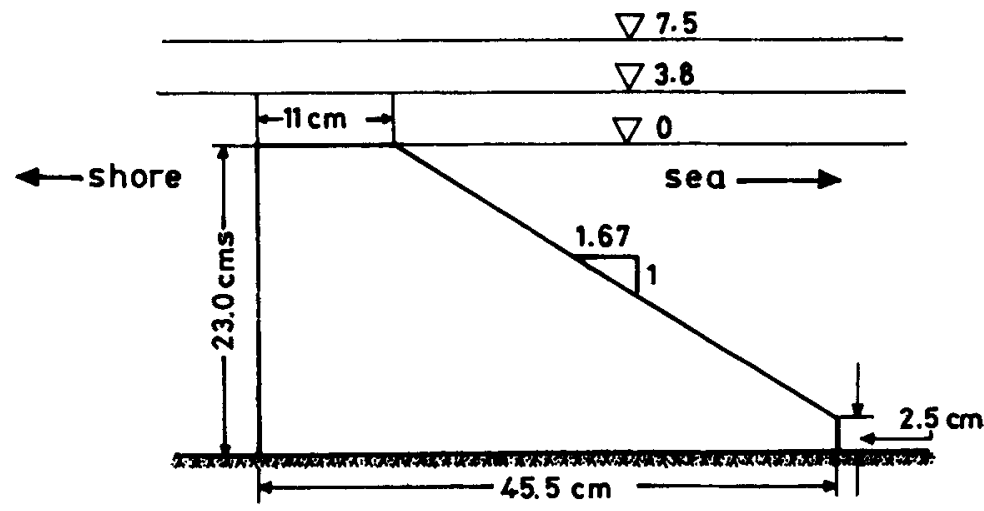

Figure 2. Submerged breakwater model. 
Table 1. Results of test series for evaluating wave reflection at the submerged breakwater

\begin{tabular}{cccccc}
\hline $\begin{array}{c}a \\
(\mathrm{~cm})\end{array}$ & $\begin{array}{c}T \\
(\mathrm{~s})\end{array}$ & $\begin{array}{c}H_{I} \\
(\mathrm{~cm})\end{array}$ & $\begin{array}{c}H_{R} \\
(\mathrm{~cm})\end{array}$ & $\begin{array}{c}K_{R} \\
\boldsymbol{H}_{R} / H_{I}\end{array}$ & $\begin{array}{c}\text { Wave } \\
\text { height } \\
\text { at gauge } \\
\boldsymbol{B}_{2}\end{array}$ \\
\hline 0.0 & 1.32 & 7.4 & 1.0 & 0.13 & 7.4 \\
0.0 & 1.32 & 9.8 & 1.1 & 0.11 & 9.8 \\
0.0 & 1.32 & 13.2 & 1.2 & 0.09 & 13.1 \\
3.8 & 1.32 & 7.6 & 0.2 & 0.03 & 7.5 \\
3.8 & 1.32 & 10.4 & 0.4 & 0.04 & 10.5 \\
3.8 & 1.32 & 13.2 & 0.7 & 0.05 & 13.2 \\
7.5 & 1.32 & 7.5 & 0.1 & 0.01 & 7.5 \\
7.5 & 1.32 & 9.9 & 0.0 & 0.00 & 9.8 \\
7.5 & 1.32 & 14.0 & 0.3 & 0.02 & 14.2 \\
\hline
\end{tabular}

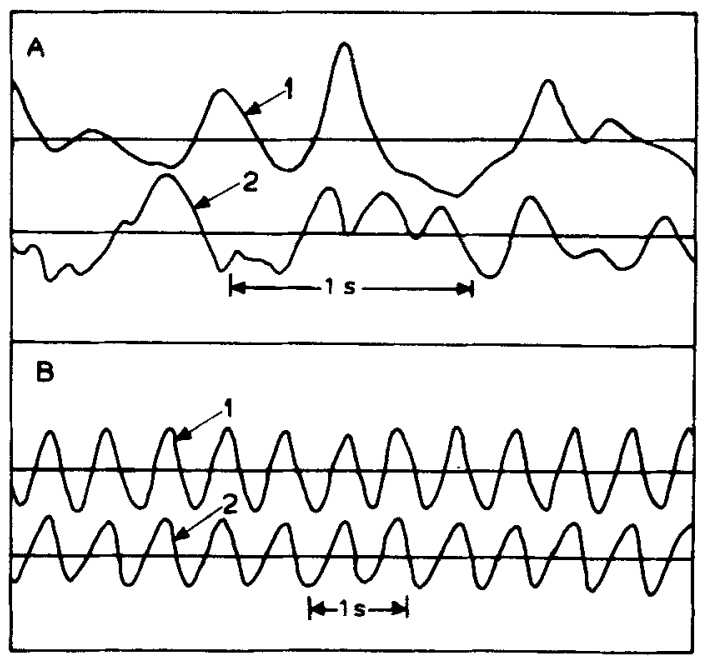

Figure 3. Sample (A) irregular and (B) regular wave records (1-incident waves; 2-transmitted waves).

waves is kept around the period of the regular waves tested above. Hence, it is assumed that the above results also apply to the irregular waves.

For the main experiments three wave gauges were established in the flume. The first one was used for a control of waves generated in the flume. The second one measured the incident waves, as mentioned above. The transmitted waves were measured at a central location of the protected area, sufficiently away from the breakwater to avoid the turbulent zone and to permit the reformation of the waves. Sample wave records are presented in figure 3 .

A total of 12 tests were conducted with irregular waves, by varying the depths of submergence $(a=0.0 ; 3.8 ; 7.5 \mathrm{~cm})$, mean wave period $\left(\bar{T}_{i}=1 \cdot 12\right.$ to $\left.1.31 \mathrm{~s}\right)$ and mean wave height $\left(\bar{H}_{i}=6.3\right.$ to $\left.11.4 \mathrm{~cm}\right)$. A listing of the tests with various parameters is presented in table 2 . Subsequently 41 tests were conducted with regular waves under the same model conditions and varying $H_{i}$ from 6.0 to $16.0 \mathrm{~cm}$ and $T_{i}$ from 1.19 to $1.55 \mathrm{~s}$. 
Table 2. Tests with irregular waves

\begin{tabular}{ccccccr}
\hline $\begin{array}{c}a \\
(\mathrm{~cm})\end{array}$ & $\begin{array}{c}\bar{T}_{i} \\
(\mathbf{s})\end{array}$ & $\begin{array}{c}\bar{H}_{i} \\
(\mathbf{c m})\end{array}$ & $\begin{array}{c}\boldsymbol{H}_{\max i} \\
(\mathrm{~cm})\end{array}$ & $\begin{array}{c}T_{i} \\
(\mathrm{~s})\end{array}$ & $\begin{array}{c}\bar{H}_{t} \\
(\mathbf{c m})\end{array}$ & $\begin{array}{c}\boldsymbol{H}_{\max } \\
(\mathbf{c m})\end{array}$ \\
\hline 0.0 & 1.12 & 7.7 & 17.3 & 0.85 & 3.5 & 8.4 \\
0.0 & 1.31 & 7.8 & 18.5 & 0.96 & 4.0 & 12.9 \\
0.0 & 1.31 & 10.8 & 20.3 & 0.97 & 4.7 & $11 \cdot 1$ \\
0.0 & 1.28 & 11.4 & 23.1 & 0.96 & 4.8 & 12.9 \\
3.8 & 1.13 & 7.4 & 15.9 & 0.94 & 4.2 & 9.9 \\
3.8 & 1.23 & 7.3 & 17.4 & 0.96 & 4.4 & 11.1 \\
3.8 & 1.24 & 7.4 & 16.6 & 1.08 & 4.6 & 14.5 \\
3.8 & 1.23 & 9.0 & 19.9 & 1.05 & 4.7 & 13.7 \\
7.5 & 1.18 & 6.3 & 13.5 & 1.06 & 5.6 & 12.7 \\
7.5 & 1.31 & 6.5 & 15.1 & 0.96 & 5.7 & 14.9 \\
7.5 & 1.30 & 8.2 & 17.6 & 1.07 & 6.8 & 16.1 \\
7.5 & 1.29 & 9.6 & 22.4 & 1.14 & 6.3 & 15.8 \\
\hline
\end{tabular}

All the records were subjected to zero up-crossing analysis and the statistical distribution of heights and periods was studied for irregular waves. The irregular waves were also subjected to spectral analysis using the autocovarience method. For this a three-minute record containing more than 100 waves was digitized at $0.08 \mathrm{~s}$ intervals in a digitizer compatible with the IBM M220M computer.

\section{Transformation of heights and periods}

The effect of a submerged breakwater on irregular waves was studied by evaluating some statistical properties of incident and transmitted irregular wave trains. Among the various statistical parameters, the probability distribution of heights and periods reflect the important statistical regularities of the wave field.

Cumulative height distributions were prepared for the three locations where measurements are made. The cumulative values are presented in the non-dimensional form by dividing individual wave heights by mean wave heights (figure 4). From figure 4A it may be seen that the wave height distribution in the relatively deeper portion of the flume is well represented by the Rayleigh function (3). But as the waves enter the shallow water and reach the breakwater the wave heights depart from the Rayleigh distribution curve (figure 4B). Similar observations of departure from the Rayleigh curve have also been made in the case of field data by Gluhovski (1968), Thompson (1974) and many others. As the waves enter shallow waters, the crests become steeper and the troughs flatter, leading to a non-Gaussian distribution of surface elevations (Thompson 1980). For the Rayleigh distribution the surface elevations should invariably be Gaussian (Longuet-Higgins 1952) and the departure of wave heights from this may be due to the shallow water effects.

A distribution function for shallow water wave heights has been suggested by Gluhovski (1968) in the following form:

$$
P(H)=\exp \left[-\frac{\pi}{4\left(1+h^{*} / \sqrt{2 \pi)}\right.}(H / \bar{H})^{\frac{2}{1-h^{*}}}\right],
$$

where $h^{*}=\bar{H} / d$. This equation, for $h^{*}=0$, takes the form of the Rayleigh distribution 


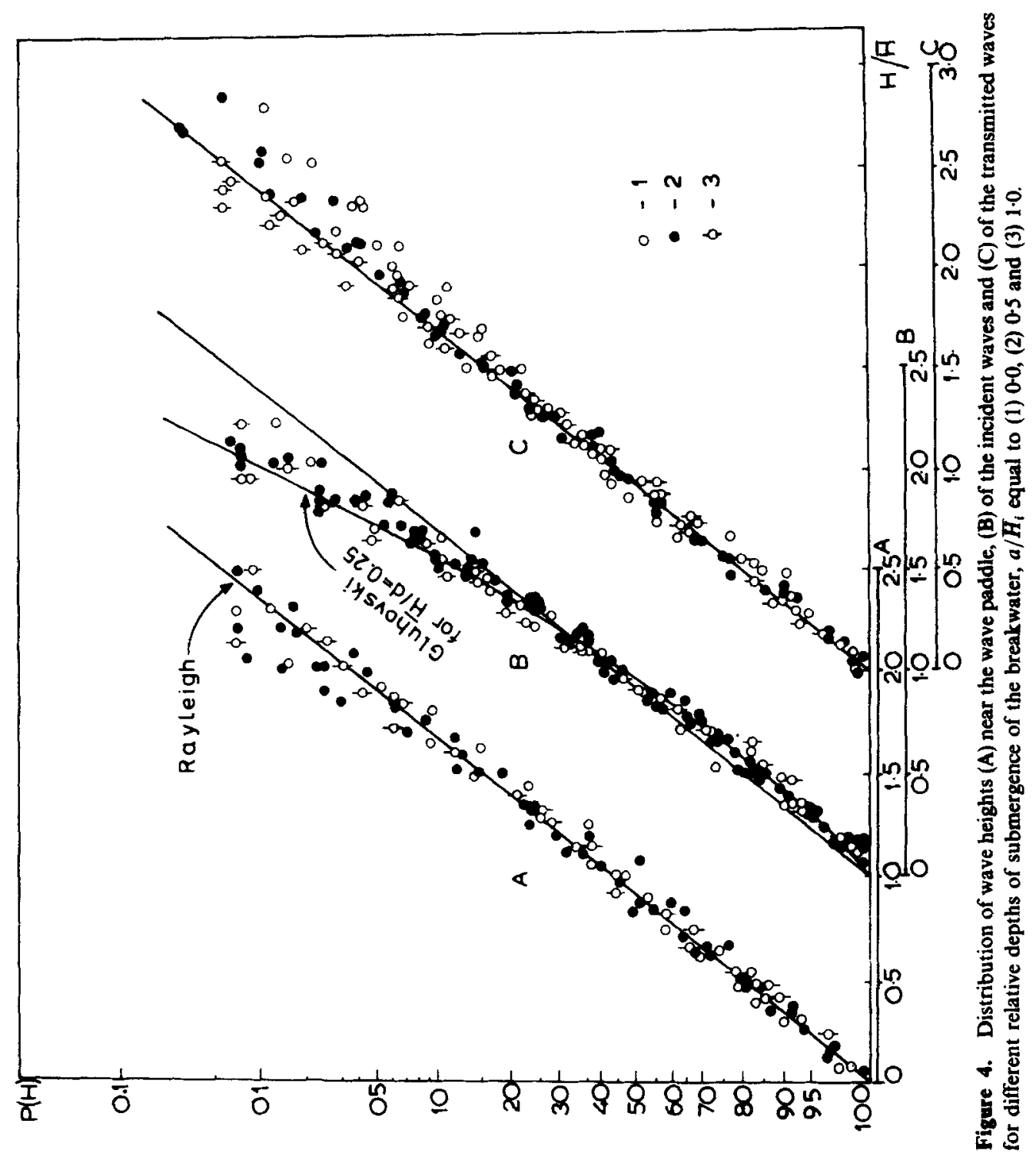


and for $h^{*}=0.5$, i.e. in the breaker zone, transforms to

$$
P(H)=\left[-\frac{\pi}{4 \cdot 8}(H / \bar{H})^{4}\right] .
$$

The distribution of wave heights in front of the breakwater (figure 4B) is satisfactorily explained by (4) for a representative value of $h^{*}=0.25$. The relative depth of submergence of the breakwater does not appear to have any significant influence on this distribution.

The transmitted waves behind the submerged breakwater, however, tend to follow the Rayleigh distribution (Figure 4C). This may be due to the non-uniform dampening of waves of different probabilities by the submerged breakwater. The higher waves are transmitted more easily than the smaller waves. The distribution of transmitted wave heights remains practically the same for the range of $a / \bar{H}_{i}$ tested.

Krilov (1956) and Bretschneider (1959) found that the periods of random waves both in deep and shallow water can be explained by the Rayleigh distribution for the square of the wave periods:

$$
P(T)=\exp \left[-0.675(T / \bar{T})^{4}\right] .
$$

The present results show conformity of the above function for the wave period distribution in relatively deeper waters (figure 5A). But, as the water depth decreases the departure of the higher periods from this distribution becomes more evident (figure 5B). The distribution pattern of the periods changes considerably as the waves cross the submerged breakwater. They clearly deviate (figure $5 \mathrm{C}$ ) from the Rayleigh distribution function for the square of the wave periods, but it is interesting to note that they follow the straight line fit of the Rayleigh function, which for the wave periods may be expressed as

$$
P(T)=\exp \left[-\frac{\pi}{4}(T / \bar{T})^{2}\right]
$$

The influence of $a / \bar{H}_{i}$, in either the incident or transmitted wave period distribution is negligible, as in the case of wave height distribution. The distribution pattern of the periods of the transmitted waves is similar to that of the transmitted heights.

These tests thus show that although the distribution functions of heights and periods are different for the incident waves, both heights and periods follow the same Rayleigh distribution function once they get transmitted beyond the submerged breakwater.

\section{Comparison of irregular and regular wave transmission}

Most of the methods presently available for the computation of wave transmission coefficient are based on a particular wave height (Goda 1969; Madson \& White 1976; Seelig 1980). Even in the case of irregular waves, the significant wave height is generally used for this purpose. The validity of this assumption and how the other irregular wave parameters are transmitted in comparison with the regular waves are examined here.

The transmission coefficient, both in the case of regular and irregular waves, is found to increase with the relative depth of submergence of the breakwater. It also increases with the wave period, longer waves are transmitted easily. In figure 6 the transmission coefficients are presented for $\bar{H}, H_{s}$ and $H_{\max }$ of irregular waves and for heights of the 


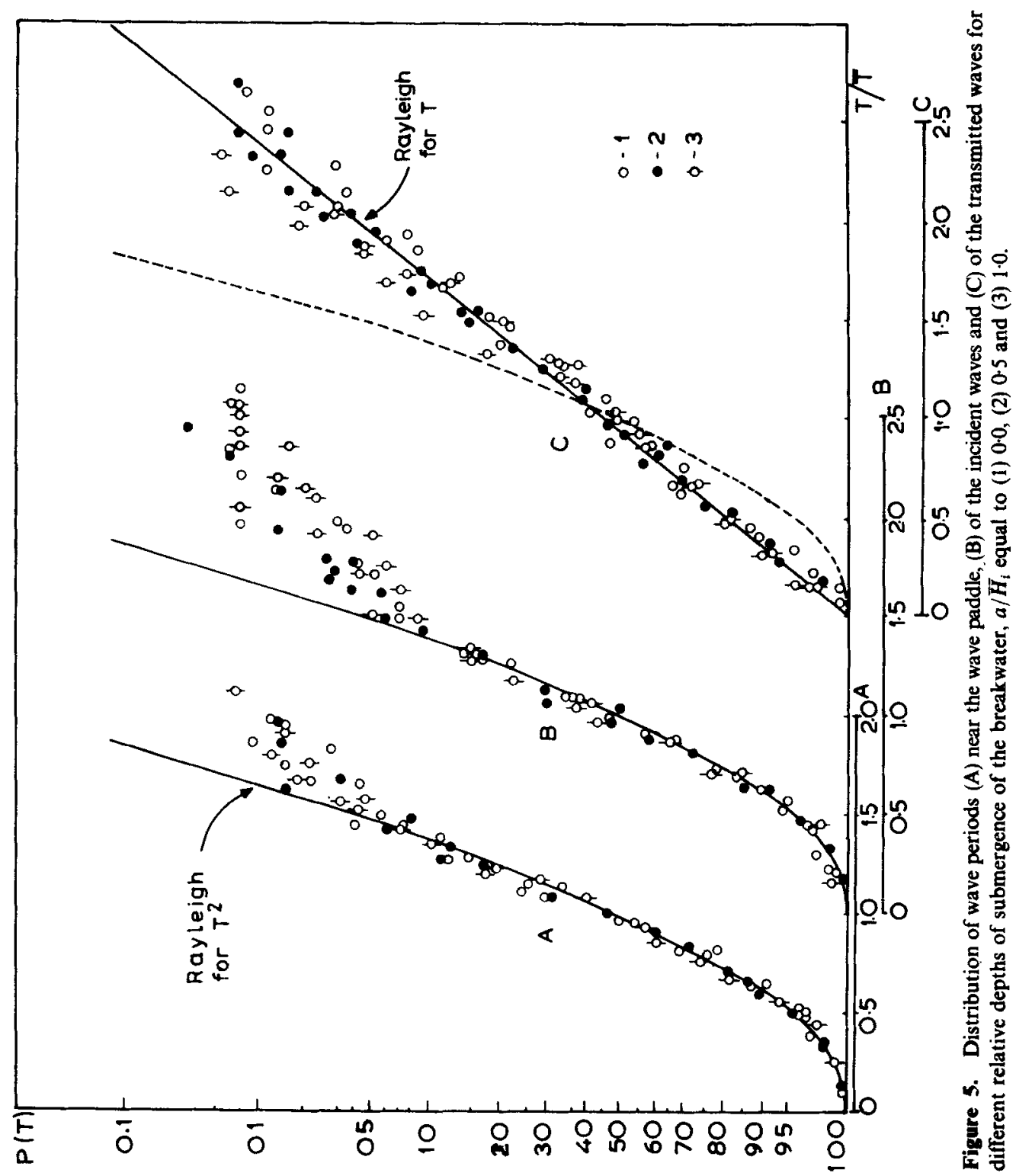



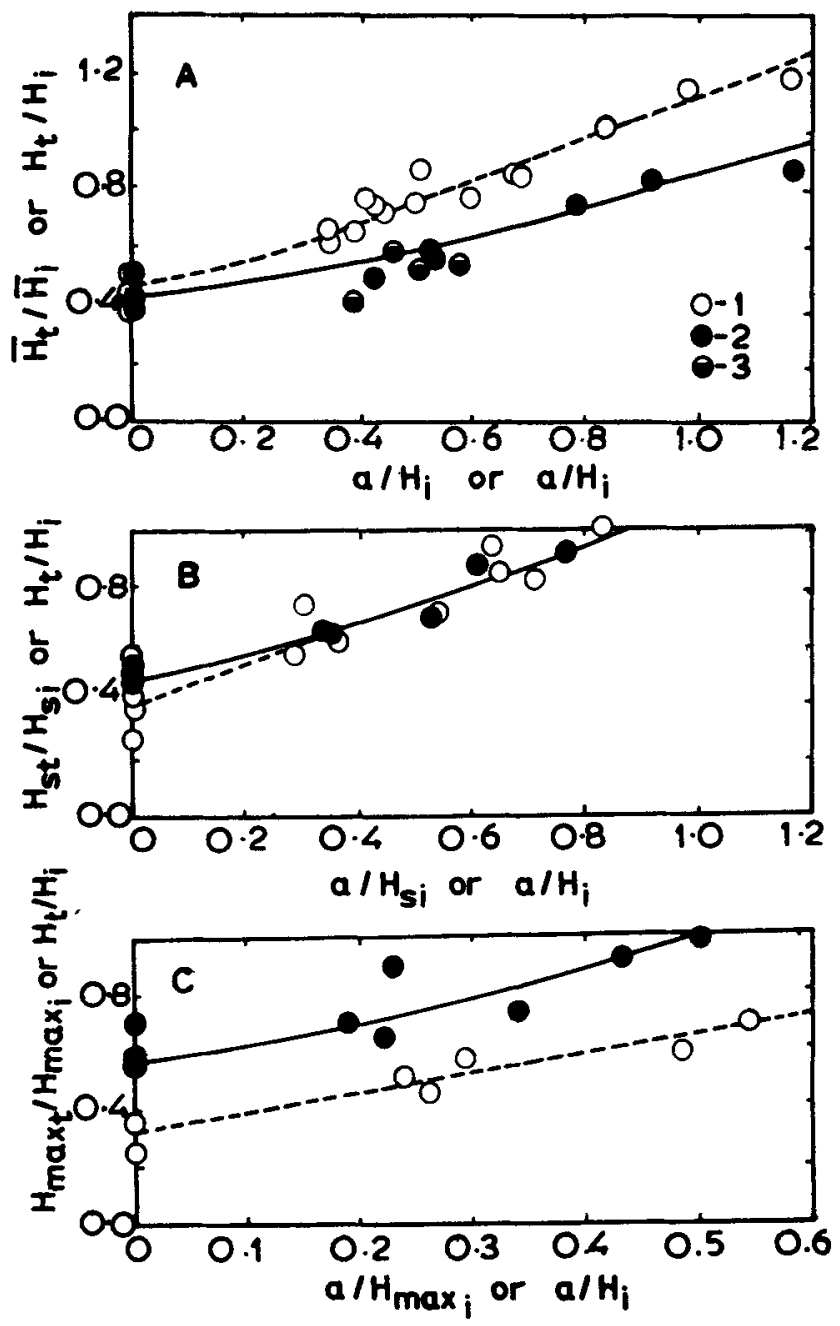

Figure 6. Transmission coefficient, $K_{T}$ for different irregular wave height parameters and corresponding regular wave heights (1-regular waves; 2 -irregular waves and 3-prototype data from Lizlov \& Natalchishin 1971)

corresponding regular waves. For waves selected for comparison the incident period (the mean period in the case of irregular waves) is kept around $1.30 \mathrm{~s}$.

In figure 6A some of the results obtained from a field test of a similar breakwater with identical bottom slopes (Lizlov \& Natalchishin 1971) are also reproduced. These confirm the results obtained from laboratory tests with irregular waves. It may be seen that the mean heights of the irregular waves give lower transmission coefficients than the corresponding regular waves. However, at the zero submergence of the breakwater the transmission coefficients of both regular and irregular waves are similar. The difference increases and at $a / \bar{H}_{i}=1 \cdot 2$, the irregular waves give $28 \%$ lower transmission coefficient than the regular waves. Further, on comparison of the significant wave heights and the corresponding regular wave heights (figure 6B), the transmission coefficients are seen to be identical except when the crest of the breakwater is at the 
water level, where the regular waves give a slightly lower value for $K_{T}$. Hence, the significant wave height may be considered to represent irregular waves in the computation of wave transmission over the submerged breakwater. A further examination of maximum height values of irregular waves (figure $6 \mathrm{C}$ ) shows that they give $50 \%$ higher transmission coefficients than the corresponding regular waves. This is in contrast to the lower values obtained in the case of mean wave heights.

Hence, for practical design of submerged breakwaters, the transmission coefficients may be estimated using significant wave heights. But it should be kept in mind that for the other irregular wave height parameters like $H_{\max }$ and $\bar{H}$ the transmission coefficients are not proportional to the significant wave heights unlike monochromatic waves. For wave heights greater than $H_{s}$, the transmission coefficient is higher and for wave heights lower than $H_{s}$, it is lower than that predicted by the corresponding monochromatic waves.

\section{Transformation of wave spectrum}

The changes in the wave spectrum as it crosses over the submerged breakwater are examined here. To simplify the comparison of the incident and transmitted spectra, the spectral density function (2) is normalized using the variance $\left(\sigma_{i}^{2}\right)$ and the peak period $\left(T_{p i}\right)$ of the incident energy spectrum. Thus the normalized nondimensional spectrum is presented as

$$
S^{*}\left(\omega / \omega_{p}\right)=S\left(\omega / \omega_{p}\right) / \sigma_{i}^{2} T_{p i}
$$

With this normalization the spectra under investigation can be arranged according to their intensity. After this operation the peak of the incident spectra will be situated at $\omega / \omega_{p i}=1$.

Typical normalized spectra of the incident waves for the three depths of submergence of the breakwater and the corresponding transmitted spectra are presented in figure 7. In all the three cases, the relatively narrow band spectra has a well-developed peak at $\omega_{i}=5.0 \mathrm{rad} / \mathrm{s}$. The smaller peaks in the incident spectra are negligible when compared to the main peak, except in the first case $\left(a / H_{i}=0\right)$, where significant secondary peaks are observed both at the lower and higher frequencies. These smaller peaks may be due to

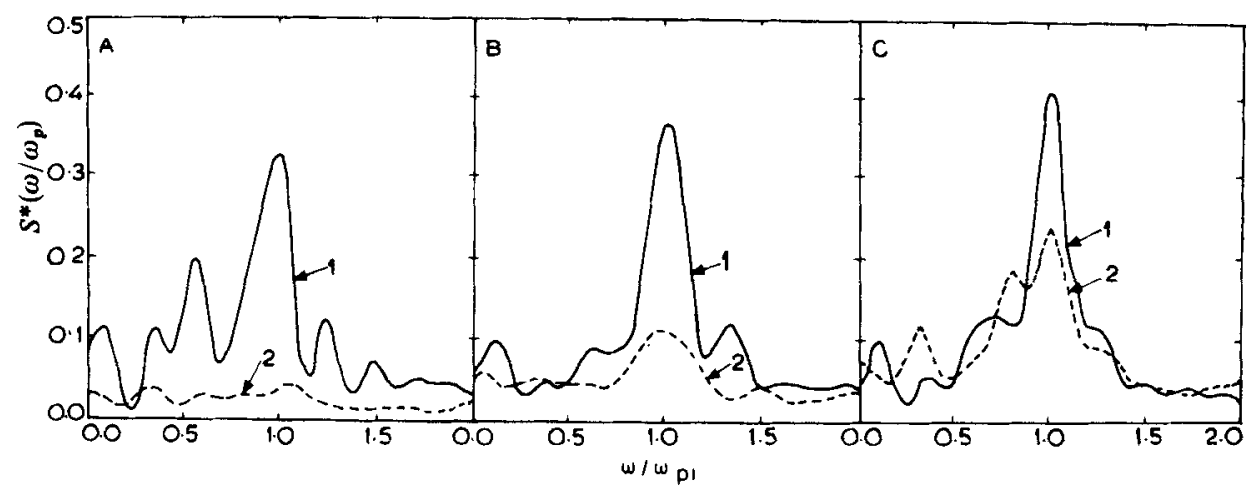

Figure 7. Typical normalized non-dimensional (1) incident and (2) corresponding transmitted wave spectra for different relative depths of submergence of the breakwater, $a / \bar{H}_{i}$ equal to (A) 0.0 , (B) 0.5 and (C) 1.0 . 
secondary processes taking place in the flume, such as sieches in the low frequency band (Krilov et al 1976) and other nonlinear processes in the higher frequency band of the spectra.

When the irregular waves cross the submerged breakwater the frequency position of the major peak of the spectrum does not change. But as expected, with an increase in the depth of submergence of the breakwater, the damping of the wave energy decreases, i.e. the energy transmission increases. For a high submergence of the breakwater, the energy at the main peak of the spectrum is distributed to a secondary peak with a slightly lower frequency. This may be due to the free passage of low frequency oscillations, beyond the breakwater subsequent to the increase in the depth of submergence.

\subsection{Transfer function}

For a more detailed analysis of the spectrum during the transmission across the submerged breakwater, the concept of transfer function (Bendat \& Piersol 1971) is utilized. Wind waves on the sea surface are treated as an ergodic stationary random process. If $x(t)$ is such a process at the entrance of a linear system and $y(t)$ the random process at the exit, then according to the theory of random processes (Bendat $\&$ Piersol 1971 ), the output spectrum of that process at the exit, $S y(\omega)$ will be related to the input spectrum at the entrance $S x(\omega)$ for $\omega>0$ by the following relationship

$$
S y(\omega)=H(\omega) S x(\omega),
$$

where $H(\omega)$ is the transfer function of this dynamic system. If $S x(\omega)$ and $S y(\omega)$ are replaced by $S_{i}(\omega)$ and $S_{i}(\omega)$ the incident and transmitted wave spectrum respectively, the transfer function for the present case may be written as

$$
H(\omega)=S_{i}(\omega) / S_{i}(\omega) .
$$

The values of the transfer function corresponding to each frequency band are computed and the results are plotted in figure 8. The figure shows that transfer function oscillates with a number of peaks and troughs. At certain frequencies the transfer function is around unity indicating total transmission of incident wave energy. The peak frequencies observed in the transfer function are called 'resonant frequencies'. These were also observed by Ouellet \& Morin (1975) and Gadre \& Kanetkar (1983) in their tests with irregular waves and breakwaters. The resonant frequencies detected in the present study are presented in table 3 for different relative depths of submergence of breakwater crest. It is observed that the resonant frequency values $\left(\omega_{r}\right)$ do not change considerably with depth and their representative values are $\omega_{r}=1 \cdot 4,3 \cdot 8,5 \cdot 6,7 \cdot 0 \mathrm{rad} / \mathrm{s}$. However, the intensity of energy transfer at these frequencies does increase with depth. The high resonance at $\omega_{r}=1.4$ may be attributed to the low frequency surf beats (Goda 1975) or sieches (Krilov et al 1976). The occurrence of other resonant frequencies in the dynamic system may be attributed to the multiple refiections behind the breakwater (Ouellet \& Morin 1975) or to the redistribution of the wave energy of the peak frequency to higher values after the wave breaks over the breakwater. But the question of why the resonance occurs specifically at these frequencies remains to be settled. The resonant frequencies above $8.0 \mathrm{rad} / \mathrm{s}$ are not clear owing to the scatter, which may be due to the presence of noise in the given process.

Ouellet \& Morin (1975) found resonant frequencies different from the ones observed 


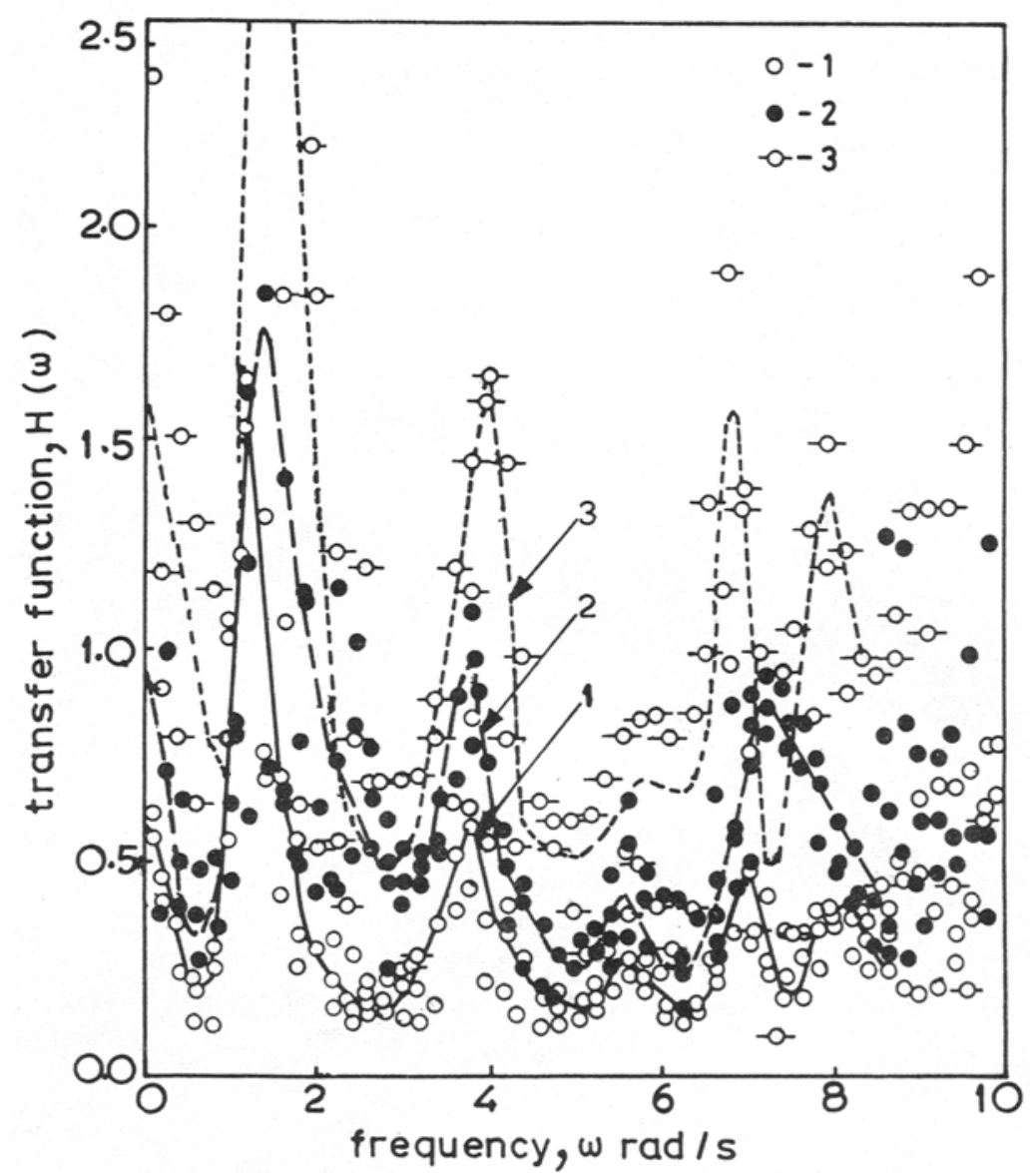

Figure 8. Transfer function, $H(\omega)$ of irregular waves for different relative depths of submergence of the breakwater, $a / \bar{H}_{i}$ equal to (1) 0.0 , (2) 0.5 and (3) 1.0 .

Table 3. Resonant frequencies for different relative depths of submergence of the breakwater

\begin{tabular}{cccccc}
\hline & \multicolumn{5}{c}{ Resonant frequency $\omega_{\mathrm{r}, \mathrm{rad} / \mathrm{s}}$} \\
\cline { 2 - 6 } & 1 & 2 & 3 & 4 & 5 \\
\hline 0.0 & 1.2 & 3.8 & 5.6 & 7.0 & 8.0 \\
0.5 & 1.4 & 3.8 & 5.6 & 7.3 & - \\
1.0 & 1.4 & 4.0 & 5.8 & 6.8 & 8.0 \\
\hline
\end{tabular}

in the present case (table 4). They reported that the resonant frequencies vary with the type of breakwater. This appears to be true, as a striking similarity is observed between the resonant frequency values of the present study, brought to prototype scale according to Froude similitude conditions, and the ones derived from Gadre \& 
Table 4. Comparison with resonant frequencies observed for other structures

\begin{tabular}{lccccc}
\hline & \multicolumn{5}{c}{ Resonant frequencies in rad/s } \\
\cline { 2 - 6 } Structure & I & II & III & IV & V \\
\hline $\begin{array}{l}\text { Submerged breakwater } \\
\text { (Present study)* }\end{array}$ & $0-31$ & 0.85 & 1.25 & 1.56 & 1.78 \\
$\begin{array}{l}\text { Subaerial breakwaters } \\
\text { (Gadre \& Kanetkar 1983) }\end{array}$ & $0.23-0.41$ & $0.73-0.83$ & $0.93-1.26$ & $1.35-1.54$ & $1.65-1.80$ \\
$\begin{array}{l}\text { Floating breakwater } \\
\text { (Ouellet \& Morin 1975)* }\end{array}$ & $0-56$ & 0.91 & 1.15 & 1.34 & - \\
$\begin{array}{l}\text { Fixed barrier } \\
\text { (Ouellet \& Morin 1975) }\end{array}$ & $0.46-0.58$ & $0.80-0.90$ & $1.05-1.15$ & $1.25-1.35$ & - \\
\hline
\end{tabular}

* Laboratory values (Scale 1:20) are brought to prototype scale

Kanetkar (1983), both representing gravity structures, in contrast to the floating breakwater and the thin barrier tested by Ouellet \& Morin (1975).

Thus spectral analysis of the irregular waves showed that the peak frequencies do not change when the waves are transmitted over the submerged breakwater. At this frequency the energy is reduced considerably beyond the breakwater. However, in this process, there exists the so-called 'resonant frequency', at which the wave energy is transferred almost completely. The depth of submergence of the breakwater appears to have a negligible effect on these frequencies, but the energy transfer at these frequencies increases as the depth increases. A comparison with other studies shows that the type of structure has a significant influence on these frequencies.

\subsection{Resonant frequencies in regular waves}

According to the spectral theory the mean height of an irregular wave train may be expressed through the energy spectrum as

$$
\bar{H}^{2}=2 \pi \int_{0}^{\infty} S(\omega) \mathrm{d} \omega .
$$

Since the transfer function $H(\omega)$ is the ratio of spectral densities and the transmission coefficient $K_{T}$ that of individual wave heights, both should give similar results according to the above relationship. Thus it is possible to compare the transfer function of irregular waves and the transmission coefficient of regular waves.

The results obtained are presented in figure 9. Although the regular waves tested had a frequency range of only 4.0 to $6.0 \mathrm{rad} / \mathrm{s}$, the oscillation observed in the case of irregular waves in this range, can also be seen in the case of regular waves. Similar oscillations have also been observed by Dick (1968), Ouellet \& Morin (1975) and Dattatri et al (1978), in regular wave tests with other types of submerged breakwaters. This leads to the conclusion that the regular waves also have resonant frequencies. Although these results are qualitative, they may have to be considered when designing submerged breakwaters. However, further regular wave tests with a wider range of frequencies are necessary to establish this point. 


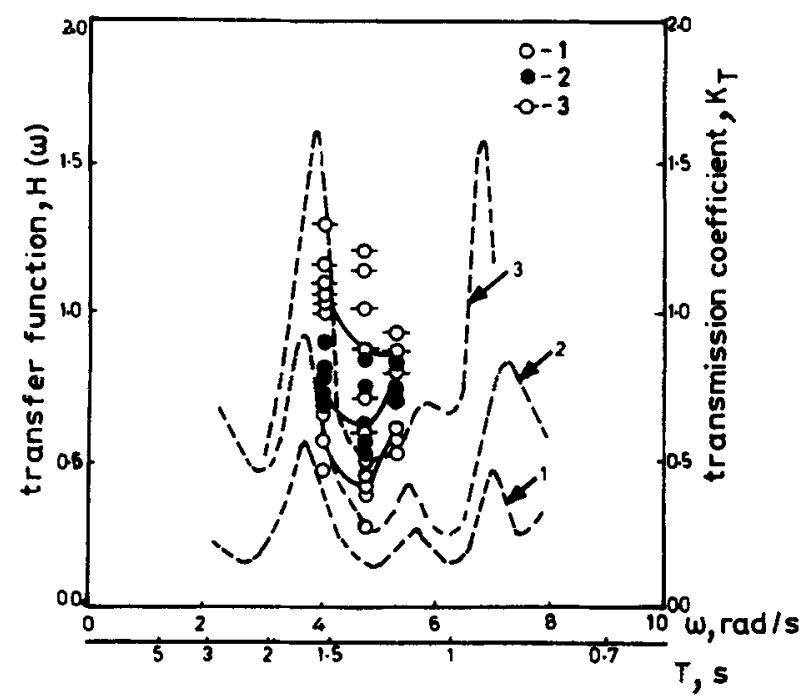

Figure 9. Transmission coefficient of regular waves, $K_{T}$ compared with the transfer function of irregular waves, $H(\omega)$ for different relative depths of submergence of the breakwater, $a / \bar{H}_{i}$ equal to (1) 0.0 , (2) 0.5 and (3) 1.0 .

\section{Conclusions}

(i) The irregular wave heights in front of the submerged breakwater follow the Gluhovski distribution and the periods follow the Rayleigh distribution for the square of the wave periods. However, in the case of periods this distribution underestimates the observed values for probabilities less than $10 \%$. The transmitted wave heights and periods follow the Rayleigh distribution. The tested range of the depth of submergence of the breakwater does not influence the distribution of heights and periods significantly.

(ii) For a fully submerged breakwater the significant height of irregular waves gives a transmission coefficient equal to that of monochromatic waves. But, the other irregular wave parameters like the mean wave height and the maximum wave height give transmission coefficients upto $28 \%$ lower and $50 \%$ higher, respectively, than the corresponding monochromatic waves.

(iii) The peak frequency of the irregular wave spectrum does not change on transmission over the submerged breakwater. It is found that there are 'resonant frequencies' at which the incident wave energy is transmitted almost completely. They occur at $\omega_{r}=1.4,3.8,5.6$ and $7.0 \mathrm{rad} / \mathrm{s}$ irrespective of the depth of submergence of the breakwater. The intensity of transmission at the resonant frequencies increases with the depth of submergence. A similar trend is also observed in the case of monochromatic waves although the tests are limited.

(iv) The use of irregular waves gives a realistic picture of the wave transmission over the submerged breakwater and the spectral analysis provides more information on the transmission process. These techniques may be adopted for rational design of submerged breakwaters. 
The laboratory studies were conducted under the guidance of Prof A V Mihailov and Dr I S Halfin of the Moscow Civil Engineering Institute, UsSR, as a part of the author's $\mathrm{Ph}$. D. dissertation. The author thanks the Director, Centre for Earth Science Studies for facilities.

\section{References}

Baba M 1978 Shore protective effectiveness of a submerged break-water in tidal seas under the action of irregular waves (in Russian), Ph.D. thesis, Moscow Civil Engineering Institute

Baba M 1981 J. Inst. Eng. (India) 61: 198-203

Bao N V 1969 Trudy Soyuzmorniproekta 27: 119-131

Bendat J S, Piersol A G 1971 Random data: Analysis and measurement procedures (New York: WileyInterscience)

Bretschneider C L 1959 Wave variability and wave spectra for wind generated gravity waves, Us Army Beach Erosion Board Tech. Rep. 118

Colonnel J M, Perry B 1968 J. Wat. Har. Coast. Eng. Div ASCE 96: 159-174

Dattatri J, Raman H, Jothi Sankar 1978 Proc. 16th Int. Conf. on Coast. Eng. ASCE Hamburg p 2153

Dick T M, Brebner A 1968 Proc. 11th Int. Conf. on Coast. Eng. ASCE p 1141

Erattupuzha J J, Raman H 1972 J. Inst. Eng. (India) 52: 310-314

Ergin A, Pora S 1971 J. Wat. Harb. Coast. Eng. Div ASCE 97: 279-293

Gadre M R, Kanetkar C N 1983 Proc Second Indian Conf. on Ocean Eng. Pune p 143

Gluhovski B H 1968 Rep. of the State Institute of Oceanology Moscow 93: 98-111

Goda Y 1969 Rep. Port Harb. Res. Inst. 18: 3-20

Goda Y 1975 Coast. Eng. Jpn. 18: 13-26

Goda Y, Suzuki Y 1976 Proc. 15th Int. Conf. on Coast. Eng. ASCE p 828

Krilov U M 1956 Rep. of the State Institute of Oceanology Moscow 33: 30-48

Krilov U M, Strekalov S S, Tzipluhin V F 1976 in Wind waves and their action on structures (in Russian), (Leningrad: Gidrometeozdat) p. 256

Lee J J, Walther J A 1974 Proc. Ocean Tech. Conf. Texas p. 951

Lizlov I A, Natalchishin G D 1970 Tr. koord. soveshch. gidrotekh. 61: 147-154

Lizlov E A, Natalchishin G D 1971 Tr. koord. soveshch. gidrotekh. 63: 184-190

Longuet-Higgins M S 1952 J. Mar. Res. 2: 245-266

Madson O S, White S M 1976 us Army CERC MR, 76-5

Mihailov A V, Krilov U M, Kasporson A A, Kapaigorodskii E M, Halfin I S, Chudinov V N 1969 Proc. XIII Cong. of IAHR Japan p. 30.

Mihailov A V, Kasparson A A, Halfin I S 1974 Gidrotekh. stroit. 12: 18-22

Nakamura M, Shiraishi H, Sasaki Y 1966 Proc 10th Int. Conf. on Coast. Eng. ASCE Tokyo p. 254

Ouellet Y, Morin Y $1975 \mathrm{~J}$. Wat. Harb. Coast. Eng. Div ASCE 101: 231-246

Seelig W N 1980 us Army CERC Tech. Rep. 80-1, p. 113

Shtephan N D, Bertman D Ya, Kalmikov S V 1970 Rep. Chornomorniproekt 2: 177-183

Thompson E F 1974 Proc WAVES-74 ASCE 1: 1-20

Thompson E F $1980 \mathrm{~J}$. Wat. Port Coast. Ocean Div ASCE 106: 285-289

Thornton E B, Calhoun R J 1972 J. Wat. Harb. Coast. Eng. Div ASCE 98: 443-460

Wiemer P, Halfin I S 1977 Nefthepromislovoe Strayitelsteva 9: 5-9

\section{List of symbols}

$A_{0} \quad$ spectral density corresponding to the main peak of the spectrum

$a$ depth of submergence of the breakwater crest

$d \quad$ the depth of water

$H \quad$ individual wave height

$\bar{H} \quad$ mean wave height

$H_{\max } \quad$ maximum wave height 


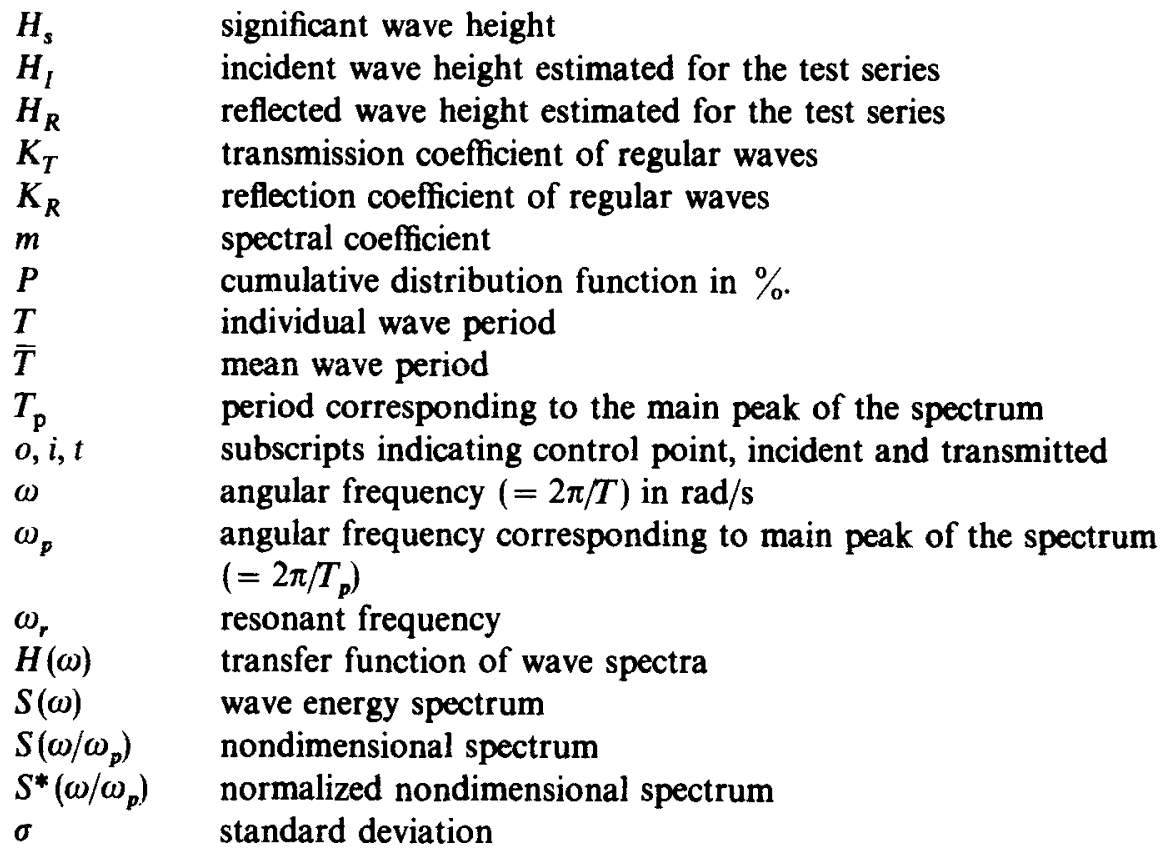

